\title{
DISTRIBUCION ALTITUDINAL DE HONGOS QUERATI- NOFILOS, EPIFITOS Y ENDOFITOS EN SUELOS DESERTICOS DEL NORTE CHILENO (II REGION, $23^{\circ} \mathrm{L} . S$ Y $68^{\circ} \mathrm{L} . \mathrm{W}$ )
}

\author{
(Altitudinal distribution of keratinophilic, epiphytic end endophytic fungi from de- \\ sertic soils in northern Chile (II Region $23^{\circ}$ S.L. and $68^{\circ} \mathrm{W}$ L.)
}

*Eduardo Piontelli. L, *M.A.Toro, S.M. \&,
** Gustavo Giusiano, ***Valia Vivar. M.
*Universidad de Valparaíso, Escuela de Medicina, Cátedra de Micología, Casilla 92 V.Valparaiso. Email< eduardo.piontelli@uv.cl> ** Universidad Nacional del Nordeste, Fac. de Ciencias Exactas y Naturales y Agrimensura, Instituto de Medicina Regional, Cátedra de Microbiología e Inmunología, Av. las Heras 772, 3500 Resistencia, Argentina ***Instituto Profesional DuocUC, Sede Valparaíso, Errazuriz 1680 Valparaíso, Chile

Palabras clave: Gradiente altitudinal, suelos desérticos, microhongos, queratinófilos, epífitos,endófitos, Chile. Key words: Altitudinal distributions, desertic soils, microfungi, keratinophilic, epiphitic,endophytic, Chile.

\section{RESUMEN}

En una zona desértica del norte chileno entre los 2200 y $4500 \mathrm{~m}$ de altura y en 2 periodos estacio-nales, se determinó la presencia y composición de las comunidades de microhongos queratinofilicos, epifitos y endófitos mediante el empleo de un anzuelo queratínico y vegetal. Las metodologías empleadas permitieron apreciar ciertos aspectos ecológicos de un grupo de hongos tolerantes al estrés y la persistencia en el tiempo de algunas de sus poblaciones en 3 gradientes altitudinales.

En 79 muestras de suelo y 67 de vegetales se obtuvieron 1111 aislamientos, repartidos en 78 géneros y 172 especies y los integrantes de los 18 géneros más frecuentes en ambos substratos y en todas las altitudes reunieron el $80 \%$ del total de presencia fúngica.

Los Zygomycetes fueron representados por 4 géneros, los Ascomycetes por 11, los Coelomycetes por 8 y los Hyphomycetes por 70 . En este último grupo los principales taxa en orden decreciente fueron: Ulocladium, Penicillium, Aspergillus, Acremonium, Alternaria, Cladosporium, Fusarium, Paecilomyces, Trichoderma, Bipolaris, Rhizopus, Aphanocladium y Verticillium. Los integrantes del género Ulocladium Aspergillus, Penicillium y Alternaria obtuvieron las mayores frecuencias en el primer escalón altitudinal en las 3 metodologías, mientras en el escalón más alto fue Penicillium, Ulocladium, Cladosporium y Acremo-nium. Ocho especies mantuvieron una alta presencia en la mayoría de los sustratos y altitudes: Ulocladium atrum, U.chartarum, Alternaria alternata, Emericella nidulans, Cladosporium cladosporioides, U.botrytis, Aspergillus fumigatus y A. niger, junto a una proporción mayoritaria de especies esporádicas o de baja frecuencia ("ruderal").

La mayoría de los Onygenales y anamorfos relacionados, se aislaron principalmente en verano entre los 2200 y los 4000m. Los más frecuentes fueron: Auxarthron umbrinum, Chrysosporium tropicum, Malbranchea gypsea y Geomyces pannorum. La presencia más alta del grupo $(17,4 \%)$ en todos los escalones y la persistencia a través del tiempo correspondió a G. pannorum.

Entre los 2200-3000m, en todos los subtratos se observaron las mayores presencias fúngicas (47 géneros y 102 spp.; 32 géneros y 63 spp.; 21 géneros y 33 spp. respectivamente) y las principales especies de la comunidad fúngica, parecen exhibir condiciones de estabilidad en el tiempo. La mayor diversidad se observó en el anzuelo queratínico y la menor en los epifitos. No hay diferencia clara entre verano e invierno y los hongos queratinofilicos responden mejor al gradiente altitudinal, mostrando mayores diversidades a menores alturas. 


\section{ABSTRACT}

In a northern desertic zone of Chile being 2.200 to $4.500 \mathrm{~m}$ high and in 2 seasonal periods, the presence and composition of keratinophilic, epiphytic and endophytic fungal communities was determined by mans of a keratinic and vegetal bait. Methodologies used enabled to assess certain ecological aspects of a group of fungi that showed stress tolerance and persistence in time of some of their populations in 3 altitudinal gradients.

One thousand one hundred eleven (1111) isolations were collected out of 70 soil and 67 vegetal samples which were divided into 78 genera and 172 species, whereas those included in the 18 genera most frequent in both substrata and in all altitudes exhibited $80 \%$ of the total fungal presence.

Zygomycetes were represented by 4 genera, Ascomycetes by 11, Coelomycetes by 8 and Hyphomy-cetes by 70 . Within this latter group the main taxa in decreasing order were: Ulocladium, Penicillium, Aspergillus, Acremonium, Alternaria, Cladosporium, Fusarium, Paecilomyces, Trichoderma, Bipolaris, Rhizopus, Aphanocladium and Verticillium. Fungi belonging to the genera Ulocladium, Aspergillus, Penicillium and Alternaria reached the highest frequencies in the first altitudinal step in the three methodologies while Penicillium, Ulocladium, Clados porium and Acremonium did the same in the highest step. Eight species kept a high presence in the majority of substrata and altitudes: Ulocladium atrum, U.char-tarum, Alternaria alternata, Emericella nidulans, Cladosporium cladosporioides, U.botrytis, Aspergillus. fumigatus and A. niger together with a major proportion of sporadic or low frequency species ("ruderal").

Most of Onygenales and related anamorphs were isolated mainly in summer within 2200 and $4000 \mathrm{~m}$. The most frequents were: Auxarthron umbrinum, Chrysosporium tropicum, Malbranchea gypsea and Geomyces pannorum. The highest presence of the group $(17,4 \%)$ in all the steps and the persistence in time was found in $\boldsymbol{G}$. pannorum.

The highest fungal presences in all the substrata were observed within 2.200-3.000 (47 genera and 102 spp.; 32 genera and 63 spp.; 21 genera and 33 spp., respectively) and the main species of the fungal community seem to exhibit stability conditions in time.

The greatest diversity could be observed in the keratinic bait and the smallest in the epiphytic fungi have a better response to the altitudinal gradient by showing major diversities at lower altitudes.

\section{INTRODUCCION}

Las regiones tropicales entre los $20-40^{\circ}$ de latitud $\mathrm{N}-\mathrm{S}$, incluyen amplias zonas desérticas donde la franja del anticiclón tropical genera sistemas de alta presión que reducen las precipitaciones en las zonas, situación que define un medio ambiente desértico considerado también como un ambiente extremo (Mc.Ginnies, 1979; Körner, 1999). Otras causas que favorecen la formación de estos ambientes, son las barreras orográficas y las corrientes oceánicas frías, condiciones propias de la zona norte de Chile-Perú, Namibia, baja California y las costas del Sahara.

Los hongos como organismos degradadores primarios, son responsables de la descomposición de la materia orgánica en los ecosistemas terrestres y su diversidad de especies está asociada a hábitat o regiones biogeográficas específicas (Kjoller \& Struwe, 1992; Rossman et al., 1998). Se reconoce la capacidad de adaptación de las poblaciones fúngica a los ambientes xéricos, no obstante, considerando las condiciones abióticas, se ha subestimado su potencial diversidad, que en los ecosistemas desérticos pueden presentar más especies fúngicas de las predecibles (Wiklow,1981).

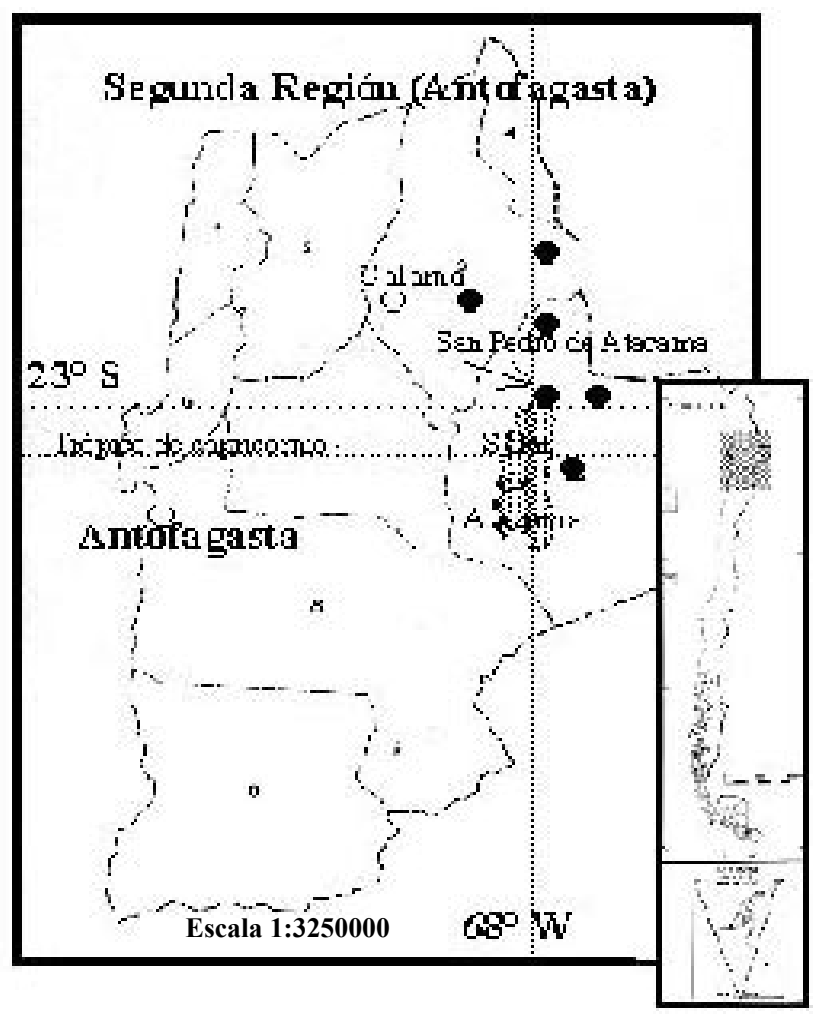

Figura 1.- Zonas de muestreo en círculos negros 

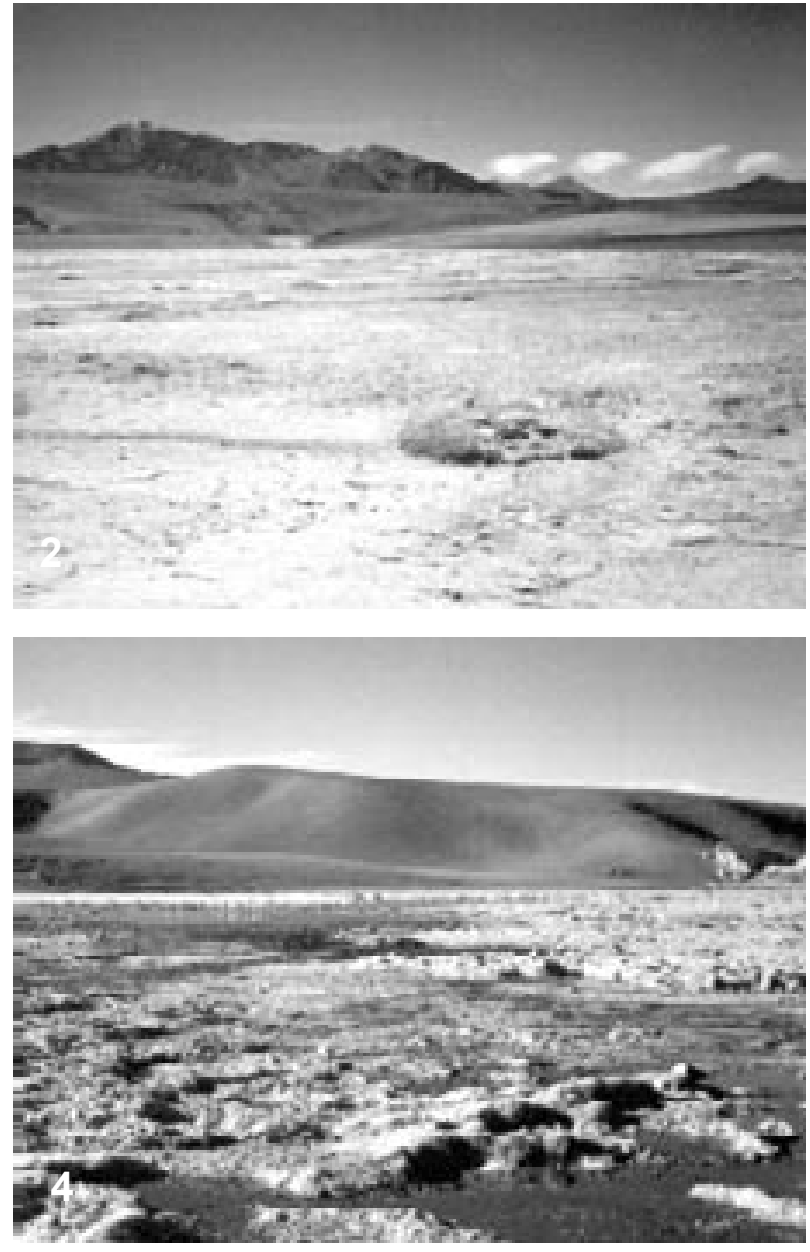

Figuras 2,3,4.- 2. Vistas panorámicas en zonas de altura intermedia $(<3000 \mathrm{~m})$ cerca de Calama. 3.- Zona de altura intermedia $(3600 \mathrm{~m})$ cercana al volcán Licancabur. 4.- Bofedal de altura $(4500 \mathrm{~m})$, cercano al paso Jaima.

La queratina y los vegetales xerófilos (arbustos y hierbas) como sustratos orgánicos, son también responsables de la diversidad y distribución de ciertos hongos geofílicos y permiten la supervivencia de las comunidades autóctonas y alóctonas en el tiempo o en condiciones nutricionales adversas. La magnitud de la diversidad fúngica en los hongos saprofíticos en hábitat o regiones particulares superiores a los $2000 \mathrm{~m}$ de altitud, es esporádica en la literatura y la especificidad de hospedadores o de substratos no puede establecerse claramente sin el aporte de mayores datos de la distribución de estos microhongos (Hyde et al., 2002)

En Chile, algunos de los estudios de microhongos de suelos en gradientes altitudinales se han efectuado principalmente en la zona central y el extremo norte del país mediante un anzuelo queratínico (Piontelli \& Caretta,1974; Piontelli et al.,1986), excluyendo la vegetación como substrato y reservorio de la comunidad.

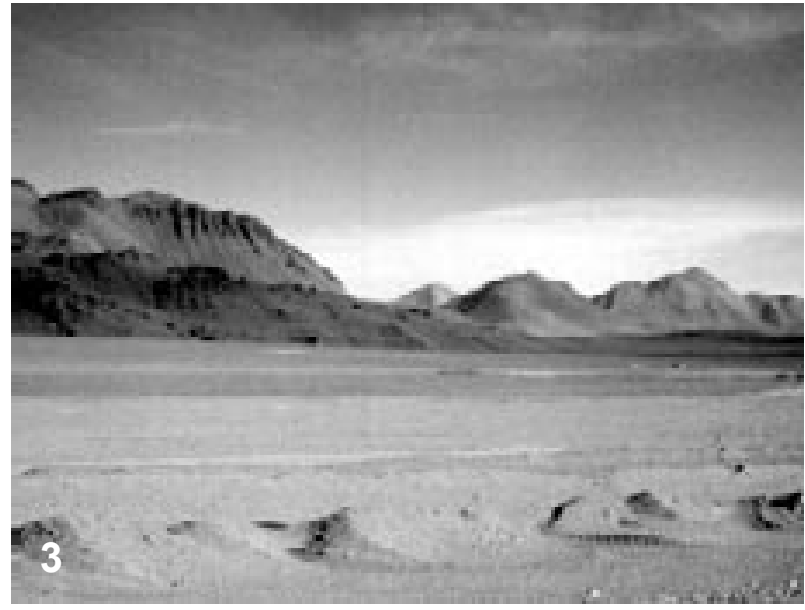

Por esta razón, hemos considerado analizar en 2 períodos estacionales (verano e invierno), mediante el empleo de anzuelos queratínicos y vegetales, la presencia de algunas microcomunidadas fúngicas en un gradiente altitudinal en ambientes desérticos áridos y escasamente antropofizados, que abarcan el salar de Atacama y las zonas cordilleranas vecinas.

\section{MATERIALES Y METODOS}

\section{1.- Aspectos biogeográficos y climáticos.}

La II Región de Chile (Antofagasta), en las zonas muestreadas (Fig. 1, 2, 3, 4), representa un ecosistema xeromórfico en su parte menos elevada (2200 m s.n.m) y un andino propiamente tal sobre $1052500 \mathrm{~m}$. Son ambientes condicionados fundamentalmente por el factor de sequedad y las condiciones de aridez son más pronunciadas a medida que se aleja de la zona precordillerana del norte hacia los contrafuertes de la zona andina, alrededor de

los $2500 \mathrm{~m}$ hacia arriba. La sequedad extrema del aire y la ausencia casi total de lluvias en el año, transforman a estas zonas en un desierto absoluto, con suelos rojos con hard pan salino, ricos en minerales y sales que sólo posee agua en los pequeños cursos de las quebradas, bofedales y en las napas freáticas superficiales de la planicie central (Quintanilla, 1983).

Presenta condiciones ecológicas extremas con un escalonamiento vertical de la temperatura. Las diurnas son a veces superiores a $\operatorname{los} 40^{\circ} \mathrm{C}$ y con notables diferencias con las nocturnas $\left(0^{\circ} \mathrm{C}\right.$ o menores $)$, especialmente en la zona andina y en ciertos períodos anuales. Esta situación que caracteriza a un desierto, convierte al de Atacama en el más inhóspito de la tierra, superando a las zonas áridas del Sahara central, Nubia(Sudán) y Lut (Irán), entre otros. Sus precipitaciones son tan escasas que no alcanzan a un milímetro de agua caída en un año. L a alta evaporación y los vientos, permiten una vegetación 
baja, achaparrada y en cojines con cactáceas xerófitas espinosas y gramíneas, entre las cuales se colectaron las siguientes:

Primer escalón altitudinal (2200-2990 m). Ephedra breana, Fabiana imbricata, Tessaria absinthioides, Atriplex atacamensis, A. microphylla, A. deserticola, Lycium deserti, Tetraglochin sp., Cistanthe celocioides, Quinopodium frigidum, Trisetum sp, Stipa sp, Disti-chlich sp. Juncus sp., Luzula sp., Cortadeira sp., Hordeum sp., Adesmia hystrix, Shinus latifolius.

Segundo escalón altitudinal (3000-4000 m). Azorella trifurcata, Vulpia sp., Fabiana imbricata, F. chilensis, Chaetantera sp, Jaborosa caulescens, Stipa sp, Atriplex oreophila, Hordeum sp, A. microphylla, Ephedra breana y especies de cactáceas/gramíneas sin determinar.

Tercer escalón altitudinal(> $\mathbf{4 0 0 0} \mathbf{~ m})$. Festuca sp., Hordeum sp., Stipa sp., Vulpia sp., Chaetantera sp., Fabiana imbricata, Atriplex deserticola y gramíneas sin determinar.

La fauna también es escasa, con excepción de sectores con algún recurso hídrico, donde abundan ciertas aves insectos y esporádicamente se detecta la presencia de algunos roedores y camélidos (guanaco y vicuña).

\section{2.-Area de estudio y recolección de material.}

El área de estudio se ubica en la II Región de Chile (Antofagasta) en un rectángulo geográfico que abarca aproximadamente desde la ciudad de Calama, los alrededores del los pueblos de San Pedro de Atacama y Toconao y las zonas altas del Tatio y paso Jama (Fig. 1, 4). Las fechas de recolección en verano fueron en el mes de Diciembre (2000) y las de invierno en Julio (2001).

a) Las muestras de suelo superficial $(3-5 \mathrm{~cm}$ de profundidad) se recolectaron en bolsas plásticas estériles, con una cuchara de metal que se limpiaba y desinfectaba con alcohol yodado. El contenido de la bolsa de unos 150-200 gramos de material, se obtenía con raspados del suelo arenoso en diferentes puntos (5-7) en un área aproximada de unos $20 \mathrm{~m}^{2}$, constituyéndose en un solo pool de muestras del área en estudio.

b) Las muestras de vegetales se recolectaron en correpondencia a las mismas áreas de las de suelo, en todos aquellos que presentaban algún tipo de vegetación. El procedimiento se basó en la introducción directa de la bolsa plástica estéril abierta sobre un manojo pequeño de las hierbas presentes, procediéndose luego al corte del material no cubierto con un cuchillo (desinfectado superficialmente con la metodología antes descrita). Se recolectaron de preferencia los vegetales con estructuras florales presentes (para su posterior identificación); cuando ésto no era posible, se incluían solo tallos y hojas. Luego se rotularon las bolsas con el mismo número correspondiente a las muestras de suelos.
Durante el transporte al laboratorio, el material colectado se mantuvo refrigerado $\left(4-6^{\circ} \mathrm{C}\right)$ en cajas térmicas durante la mayor parte del tiempo. La misma metodología de recolección, mantenimiento y transporte se usó para el muestreo de invierno

Los muestreos de invierno se realizaron en las mismas zonas (áreas marcadas) que los de verano para que la recolección de los vegetales fuera coincidente.

Los números de muestras de suelo y vegetales colectados en el muestreo de verano y de invierno en los diferentes transectos altitudinales fueron los siguientes:

$\begin{array}{ccc}\text { Verano: } & \text { Suelos }(\mathrm{n}=49) & \text { Epifitos }(\mathrm{n}=42) \\ 2200-2990 \mathrm{~m} & 31 & 24 \\ 3000-4000 \mathrm{~m} & 12 & 12 \\ >\text { los } 4000 \mathrm{~m} & 6 & 6 \\ \text { Invierno: } & \text { Suelos }(\mathrm{n}=30) & \text { Epifitos }(\mathrm{n}=25) \\ 2200-2990 \mathrm{~m} & 17 & 12 \\ 3000-4000 \mathrm{~m} & 6 & 6 \\ >\operatorname{los} 4000 \mathrm{~m} & 7 & 7\end{array}$

\section{3.- Siembra del material, métodos de observación,} cultivos y determinación fúngica.

Antes de su cultivo, todas las muestras se congelaron a $-20^{\circ} \mathrm{C}$ por una semana para evitar el desarrollo de acaros. La presencia de los taxa fúngicos, en todas las metodologías empleadas, se contabilizó una sola vez en cada placa, no importando si éstos se presentaban varias veces en la misma o en el duplicado.

a) Queratinófilos. Empleando la técnica de Vanbreuseghem (1952) modificada, cada muestra de suelos se dispensó en duplicado en 2 placas de Petri estériles de $10 \mathrm{~cm}$ de diámetro, tratando que su contenido no sobrepasara la mitad de su altura, luego estas se humedecieron agregando $10 \mathrm{cc}$ de agua destilada que contenía $0,25 \mathrm{~g} / 1 \mathrm{de}$ cloramfenicol y $0,4 \mathrm{~g} / \mathrm{l}$ de actidiona. Trozos cortos de $1-2$ $\mathrm{cm}$ de pelo humano estéril se dispersaron homogéneamente sobre la superficie, para luego incubar las placas a $25^{\circ} \mathrm{C}$ durante 2 semanas. Posteriormente se mantuvieron por un período de 2 a 3 semanas a la temperatura ambiente del laboratorio $\left(20-24^{\circ} \mathrm{C}\right.$ en verano y $15-18^{\circ} \mathrm{C}$ en invierno). Cuando era necesario controlar la humedad se agregaba nuevamente agua destilada.

El crecimiento fúngico sobre el pelo se observó mediante lupa estereoscópica después de las primeros 2 semanas de cultivo y cada 7 días posteriormente hasta completar 5 semanas. La identificación se efectuó mediante observaciones con lupa estereoscópica y preparaciones para microscopía en lactofenol con azul de algodón.Todos los hongos con mayor frecuencia de presencia, no pertenecientes a los Onygenales o géneros relacionados, se cultivaron en agar papa dextrosa, mientras estos últimos se cultivaron en agar harina de maíz.

Muchas de las determinaciónes a nivel de género 
y especie, cuando fue posible, se hicieron directamente del substrato o apoyándonos en las características de cultivo, la morfometría microscópica de los aislamientos y utilizando las monografías correspondientes.

b) Epífitos.-Empleando la técnica de cámara húmeda, se dispusieron varios $(5-7)$ trozos $(2-3 \mathrm{~cm})$ de cada vegetal sobre la superficie de agar agua en placas de Petri de $10 \mathrm{~cm}$, para luego incubarlas a temperatura ambiente durante 3 semanas. Las observaciones se realizaron entre el $7^{\circ}$ y $21^{\circ}$ días. Las determinaciones de los hongos se efectuaron mediante observación directa sobre el sustrato y preparaciones para microscopia; cuando era necesario, se hicieron subcultivos en agar papa dextrosa (PDA).

c) Endófitos.- Cada una de las muestras vegetales se cortó en trozos de $2-3 \mathrm{~cm}$, para luego proceder a su esterilización superficial con una solución de alcohol etilico al $70 \%$ por 2 minutos, luego con Hipoclorito de Sodio al $5 \%$ por 5 minutos, seguido de tres lavados con agua destilada estéril. Posteriormente los trozos (5-7) esterilizados se dispusieron sobre placas de Petri con agar agua y se incubaron a temperatura ambiente durante 4 semanas. Las observaciones y determinaciones se realizaron empleando la misma metodología que para los epífitos.

4) Análisis de resultados.- Para el análisis de los resultados se empleó el número y porcentaje de aislamientos de géneros y especies, la relación entre altitudes y estaciones y el índice de diversidad de Shannon \& Weaver.

\section{RESULTADOS}

\section{A) Generalidades}

En nuestra investigación, la frecuencia de ocurrencia fúngica detectada en todos los puntos de muestreo ( $\mathrm{n}=79$ suelos y $\mathrm{n}=67$ vegetales), según metodología, permitió reconocer ya sea directamente sobre el substrato o en subcultivos la riqueza total de especies representada por 1111 aislamientos, repartidos en 78 géneros y 172 especies. El $80 \%$ del total de presencia fúngica correspondiente a los grupos de taxa más frecuentes en ambos substratos y en todas las altitudes, se incluye en Tabla 1. Esta no incorpora los taxa esporádicos (50 géneros) cuya presencia se registró una o pocas veces. Los Zygomy-cetes fueron representados por 4 géneros (Absidia, Mucor, Rhizopus y Syncephalastrum), los Ascomycetes por 11 géneros (Amauroascus, Aphanoascus, Auxar-thron, Chaetomidium, Chaetomium, Emericella, Eurotium, Gymnascella, Gymnoascus, Melanospora y Microascus), los Coelomycetes por 8 (Ascochyta, Camarosporellum, Camarosporium, Chaetodiplodia Coniothyrium, Lasiodiplodia, Phoma, Stagonospora), y los Hyphomycetes por 70 géneros (a veces asociados a sus teleomorfos). En este último grupo los principales taxa en órden decreciente correspondieron a: Ulocladium, Penicillium, Aspergillus, Acremonium, Alternaria, Cladosporium, Fusarium, Paecilomyces, Trichoderma, Bipolaris, Rhizopus, Aphanocladium y Verticillium. Ocho especies mantuvieron una alta presencia en la mayoría de los sustratos, técnicas de aislamiento y altitudes: Ulocladium atrum, U.chartarum, Alternaria alternata, $\boldsymbol{A}$. nidulans (y su teleomorfo), $\mathbf{C l a}$ dosporium cladosporioides, U.botrytis, A. fumigatus y $A$. niger.

Los integrantes de los géneros Ulocladium, Aspergillus, Penicillium y Alternaria, fueron en el primer escalón altitudinal los de mayor presencia en las 3 metodologías, especialmente en los sustratos con queratina y vegetales. En el segundo escalón, Ulocladium, PeniciIlium, Aspergillus y Acremonium, mientras en el tercero Penicillium, Ulocladium, Cladosporium y Acre- monium (Tabla 1).

Los $\mathrm{pH}$ de los suelos en el primer escalón oscilaron entre un mínimo de 6,1 a 9,1 , pero el $85 \%$ de las muestras mostró un $\mathrm{pH}$ alcalino entre 7,3 y 8,3. En el segundo escalón el $\mathrm{pH}$ se acercó a la neutralidad con un promedio de 7,2, mientras en el escalón más alto se observó una leve acidez, con un promedio de $\mathrm{pH} 6,85$.

Las mayores frecuencias de presencia correspondieron al substrato queratínico y a los epífitos en verano en el primer escalón, los otros escalones en especial el más alto, presentaron una menor presencia fúngica (Tabla 1). La mayor diversidad (Shannon-Weaver) se observa en el anzuelo queratínico y la menor en los epífitos. No hay diferencia clara entre verano e invierno y los hongos queratinofílicos responden mejor al gradiente altitudinal, mostrando mayores diversidades a menores alturas (Gráfico 1).

\section{B) Onygenales queratinofílicos/líticos y anamorfos relacionados.}

Casi todos los taxa de Onygenales queratinofílicos (9 de 10 géneros y 13 de 14 especies), se aislaron principalmente en verano entre los $2200(\mathrm{n}=22)$ y los $4000 \mathrm{~m}(\mathrm{n}=12)$, mientras en invierno solamente se aislaron 3 géneros y 3 especies bajo los $3000 \mathrm{~m}$. Las especies dominantes fueron Auxarthron umbrinum, Chrysosporium tropicum y Malbranchea gypsea. Sobre los $4000 \mathrm{~m}(\mathrm{n}=9)$, los de mayor presencia fueron Geomyces pannorum y escasamente Apha-noascus keratinophilus y Trichophyton terrestre (ambos solo en invierno). La persistencia a través del espacio y el tiempo en todos los escalones correspondió a

G. pannorum presentando sobre $10 \mathrm{~s} 4000 \mathrm{~m}$ la mayor presencia del grupo. 
Tabla 1.- Grupos de taxa de hongos filamentosos con mayores frecuencias de presencia aislados en gradiente altitudinal en zonas del norte chileno.

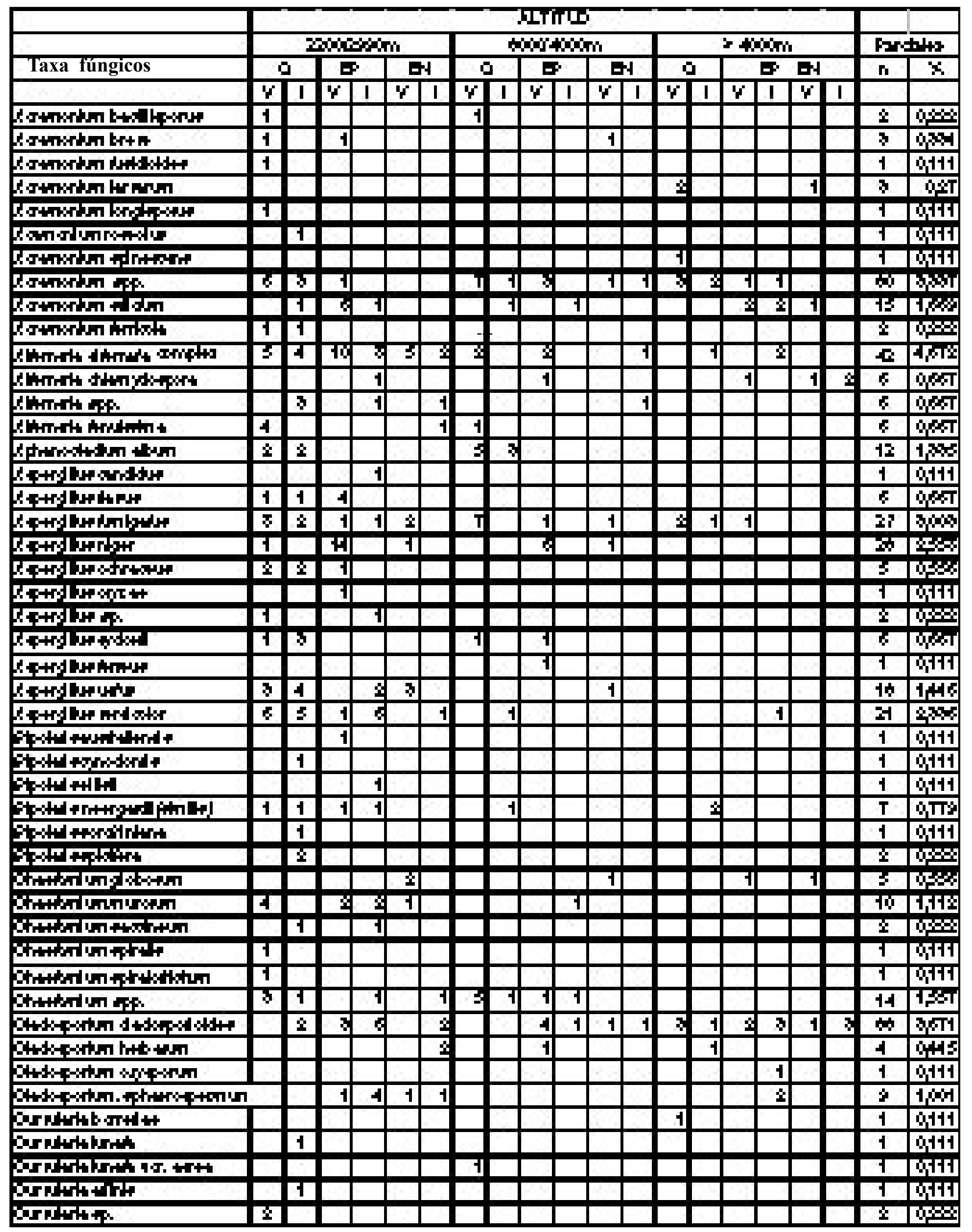

Q= Queratinófilos; EP=Epífitos; EN=Endófitos; V=Verano; I=Invierno 
(Continuación Tabla 1)

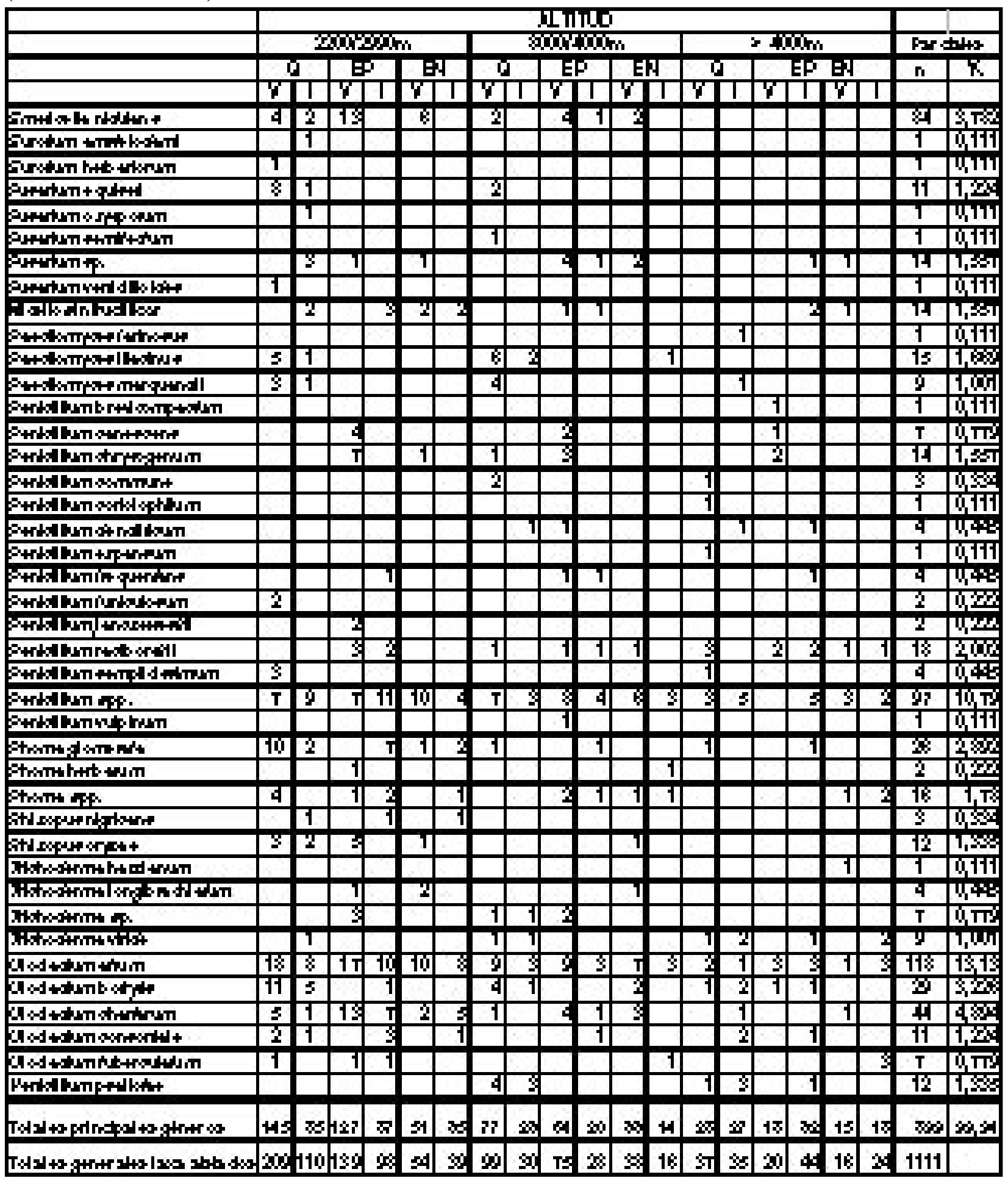

El 54,3\% de los taxa se aislaron bajo los 3000m, el $26,1 \%$ entre los $3000-4000 \mathrm{~m}$ y el $19,6 \%$ sobre 1 os $4000 \mathrm{~m}$ (Gráfico 2, Tabla 2).

Ninguno de los Onygenales y anamorfos relacionados se detectaron como epífitos ni como endófitos.
C) Taxa queratinofílicos excluyendo los Onygenales

Este grupo fue el mayoritario en presencia fúngica, especialmente en el primer escalón con 47 géneros y 102 especies en ambos períodos estacionales (187 aislamientos en verano y 107 en invierno), representados por 38 géneros 


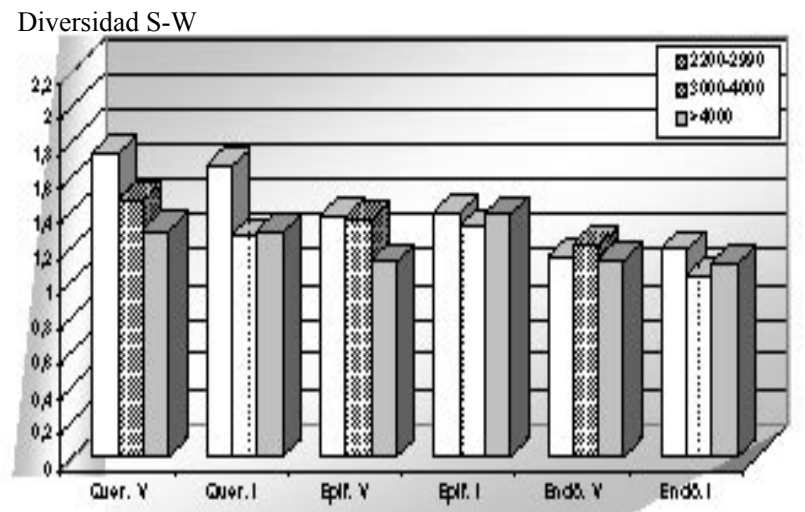

Quer.V = queratinofílicos verano; Quer. I = queratinofílicos invierno; Epif.V= epifítos verano; Epif. I= epífitos invierno; Endó. $\mathrm{V}=$ endófitos verano; Endó. $\mathrm{I}=$ endófitos invierno.

Gráfico 1. Diversidad de Shannon en los distintos gradientes altitudinales en invierno y verano

de Hyphomycetes (63\% dematiáceos), 5 Ascomycetes, 4 Zygomycetes y 2 Coelomycetes. En el segundo escalón se detectaron 26 géneros y 46 especies (99 aislamientos en verano y 30 en invierno) representados por 20 géneros de Hypho-mycetes (50\% hialinos), 3 Ascomycetes y 1 Coelomy-cetes, mientras que en el tercero, sólo 16 géneros y 34 especies ( 37 aislamientos en verano y 35 en Invierno), representados por 14 géneros de Hyphomycetes (57\% dematiáceos) y 2 de Coelomycetes.

Los taxa que demostraron una presencia constante en todos los escalones altitudinales pero casi siempre en

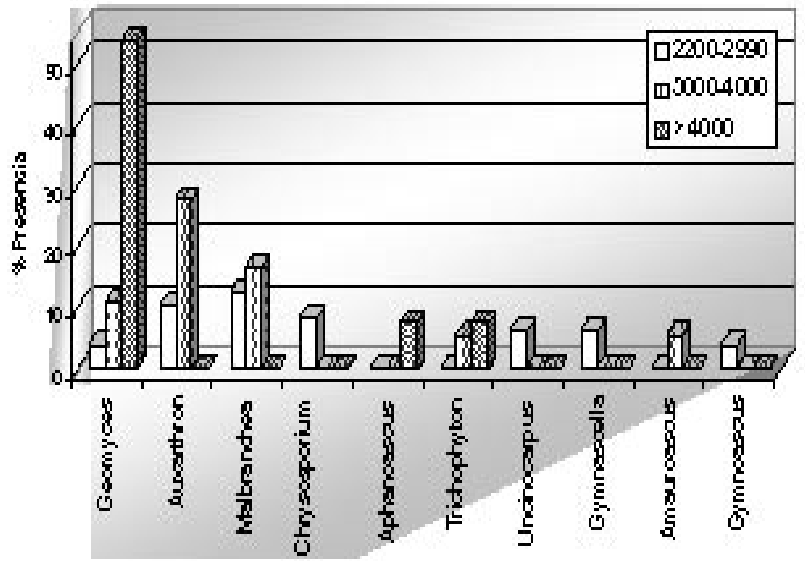

Gráfico 2: Total géneros de Onygenales queratino-líticos/filicos y sus anamorfos asociados según altitud y número de muestras

forma decreciente hacia el escalón más alto fueron: Ulocladium atrum, Penicillium spp., U.botrytis, Acremonium spp., Aspergillus fumigatus y Phoma glomerata (Tabla 1).

La estructura de los 6 géneros integrantes de la comunidad queratinofílica con mayor frecuencia de presencia por muestra, no sufre cambios importantes, se mantiene en todos los escalones, con pequeñas variaciones: Ulocladium, Penicillium, Aspergillus (incluyendo sus teleomorfos en Emericella y Eurotium), Acremo-nium, Phoma y Alternaria. Penicillium, Acremoniun y Cla-

Tabla 2.- Onygenales y anamorfos relacionados aislados en gradiente altitudinal

en zonas del norte chileno.

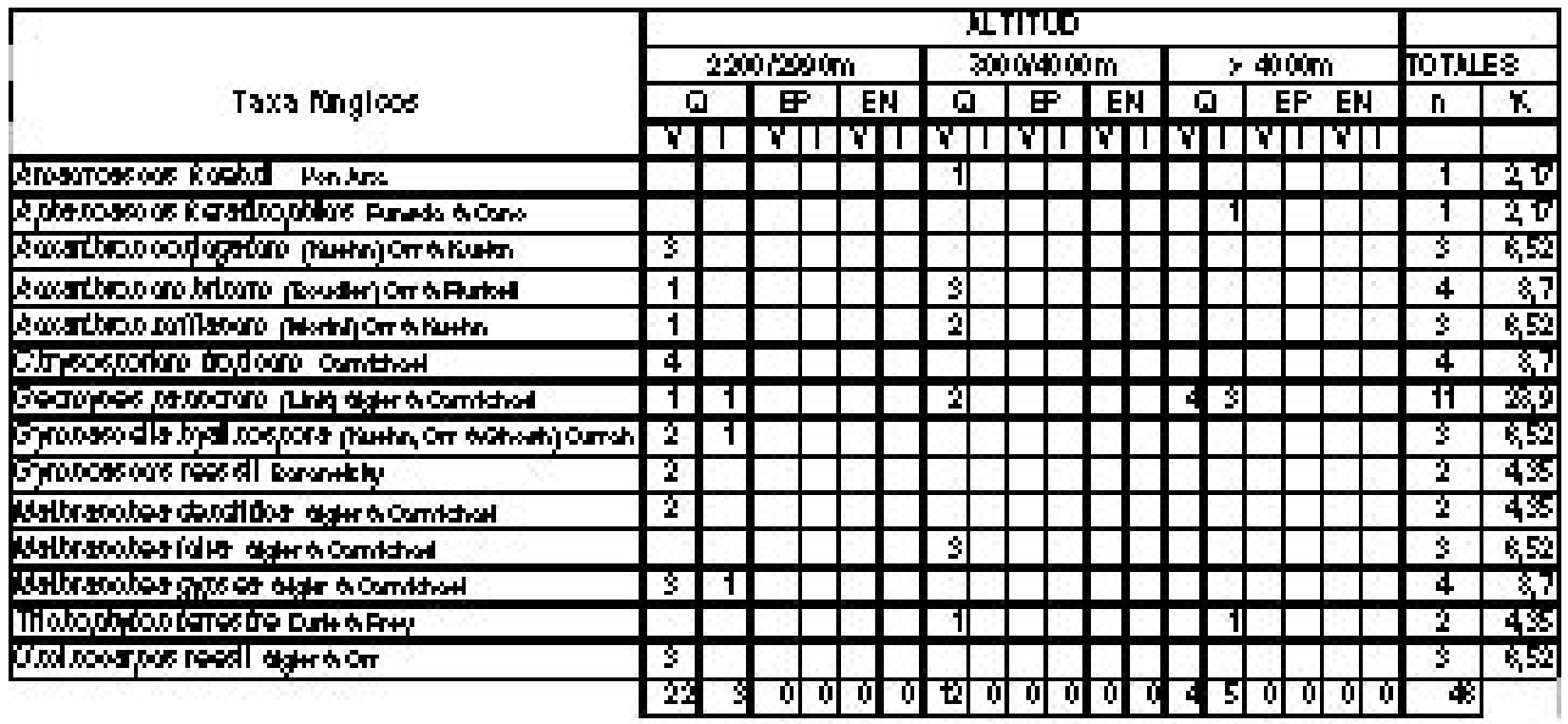

$\mathbf{Q}=$ Queratinófilos $; \quad$ EP $=$ Epífitos $; \quad$ EN $=$ Endófitos $; \quad$ V = Verano $; \quad I=$ Invierno 


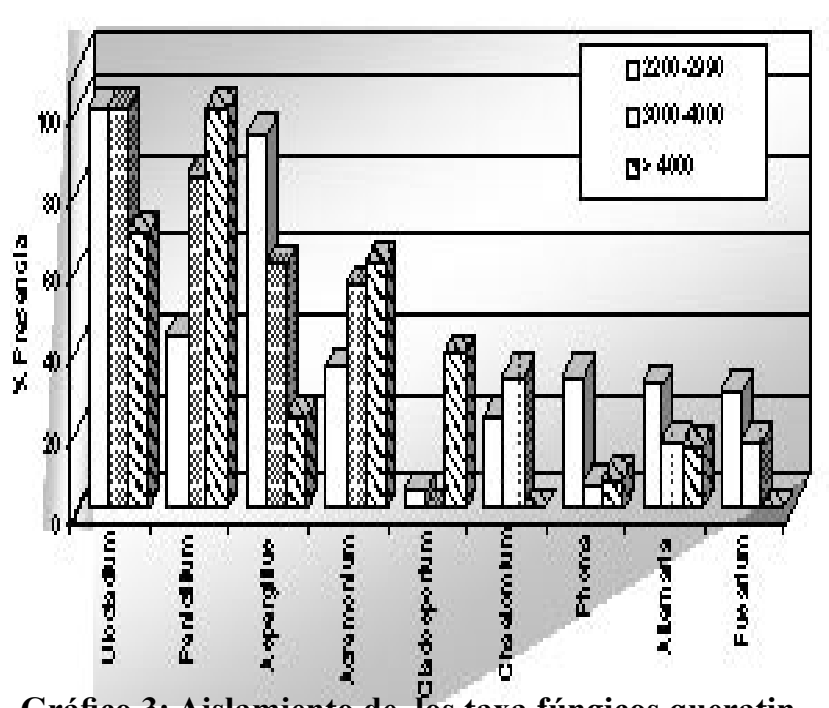

Gráfico 3: Aislamiento de los taxa fúngicos queratinofílicos según altitud y número de muestras

dosporium aumentan su porcentaje de presencia hacia el escalón más alto, en especial Penicillium. Chaetomium y Fusarium no se presentaron en el último escalón (Gráfico 3, Tabla 1).

Dentro de los hongos esporádicos presentes al menos en 2 escalones, se destacan: Aphanocladium album*, Engyodontium parvispora, Fusariella bizozzeriana, Myrothecium carmichaelii, Oidioden-drum griseum, Papulaspora sp.y Verticillium psaliotae* (*En Tabla 1).

Un $45 \%$ de las especies queratinofílicas se detectaron también como epífitos.

\section{B) Epífitos}

Sobre los diversos sustratos vegetales entre los 2200-2990m, se obtuvieron 139 aislamientos en verano y 98 en invierno, detectándose en ambos períodos, 32 géneros y 63 especies fúngicas, representadas por 3 Zygomycetes, 7 Ascomycetes, 6 Coelomycetes y 47 Hyphomycetes (60\% hialinos). Entre los 3000-4000m se obtuvieron 75 aislamientos en verano y 28 en invierno con un total de 24 géneros y 44 spp., representadas por 4 Ascomycetes, 5 Coelomycetes y 33 Hyphomy-cetes (55\% hialinos). Sobre los 4000m se obtuvieron 20 aislamientos en verano y 44 en invierno, con un total de 22 géneros y 37 spp., representadas por 1 Ascomycetes, 6 Coelomycetes y 30 Hyphomycetes (56,7\% hialinos) (Tabla. 1). Los 3 taxa vegetales dominantes en todas las altitudes fueron representados por especies de Atriplex (A.microphilla y A.atacamensis), Ephedra (E.briana) y Fabiana (F.imbricata y F.chilensis), las cuales en conjunto soportaron el $40 \%$ de la presencia fúngica. Entre los 2200 y $4000 \mathrm{~m}$, su representatividad fue similar, 45 y $46 \%$ respectivamente. Sobre los $4000 \mathrm{~m}$, estos vegetales se presentaron en menor proporción y sólo Fabiana mostró diferencias en los 3 escalones altitudinales (2,1- 24,3 y $11 \%$ respectivamente). Los taxa fúngicos dominantes en ellas, correspondieron a los géneros Ulocladium, Aspergillus y Penicillium, que representaron el 64\% del total de presencia, con las especies: Ulocladium atrum, U.chartarum, Aspergillus niger, Emericella nidulans, Penicillium chrysogenum y P.raciborskii. Aún cuando Atriplex fue el vegetal más muestreado $(\mathrm{n}=16)$, Ephedra con la mitad de representatividad $(n=8)$, obtuvo proporcionalmente la mayor presencia fúngica.

Especies de Ulocladium, Alternaria, Acremonium, Penicillium, Cladosporium y Trichoderma se detectaron en estos 3 substratos vegetales en todas las altitudes analizadas (Gráfico 4), siendo Aspergillus el género con la mayor diversidad de especies en el primer escalón altitudinal y Penicillium en los otros. Las especies de Ulocladium obtuvieron las mayores frecuencias de presencia en el primer escalón. Otros géneros se presentaron sólo en algunos de estos escalones, pero siempre en forma mayoritaria entre los 2200-3000m (Gráfico 4, Tabla 1).

La estructura de los 6 géneros integrantes de la comunidad epifítica con mayor frecuencia de presencia en las muestras es bastante similar a la observada colonizando el anzuelo queratínico. Penicillium se mantiene con la máxima presencia en los tres escalones, mientras Ulocladium, Aspergillus (incluyendo un teleomorfo en Emericella), Alternaria, Chaetomium y Trichoderma, van disminuyendo hacia el tercer escalón; aumentan hacia el tercer escalón Cladosporium y Acremonium. Aureobasidium tiene un comportamiento diferente con una máxima presencia en el segundo escalón (Gráfico 4).

Dentro de los hongos esporádicos que se presentaron por lo menos en 2 escalones se destaca: Ascochyta sp. Beauveria bassiana, Coniothyrium palmarum y

Heteroconium chaetospira (No incluidos en Tabla 1).

Un $62 \%$ de las especies espífitas se detectaron también como endófitos.

\section{D) Endófitos.}

Como colonizadores internos, se obtuvieron en ambos períodos estacionales en el primer escalón 21 géneros y 33 spp.(con una mayor presencia y diversidad en verano), representados principalmente por 19 taxa de Hyphomycetes ( 68,4\% dematiáceos), 4 Ascomycetes, 4 Coelomycetes y 2 Zygomycetes. En el segundo escalón se obtuvieron en ambos períodos un total de 18 géneros y 27 spp.(mayor presencia y diversidad en verano), representadas también en su mayoría por 20 taxa de Hyphomycetes (55\% hialinos), 4 Coelomycetes, 2 Ascomycetes y 1 Zygomycetes. En el escalón más alto un total de 17 géneros y $22 \mathrm{spp}$. (mayor presencia y diversidad en invierno), representados en su mayoría por 16 taxa de Hyphomycetes 


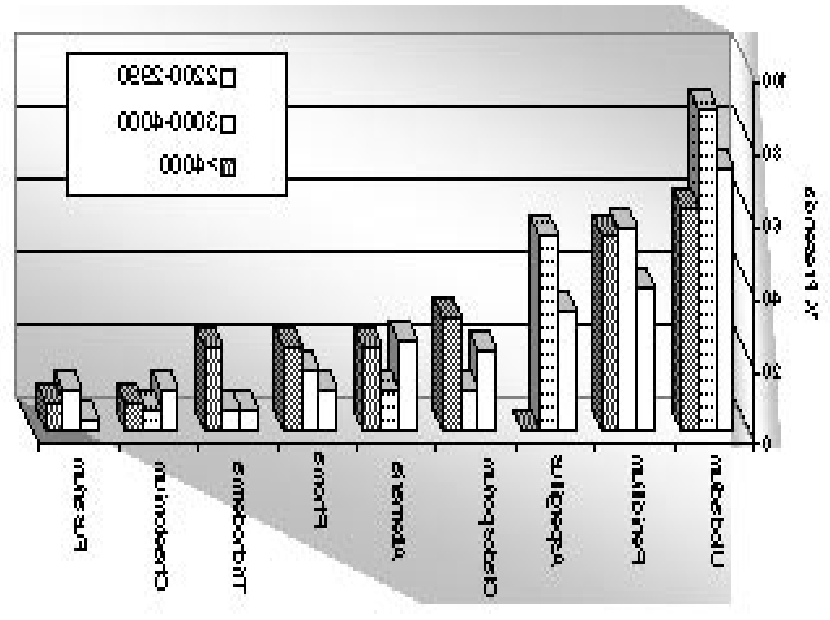

Gráfico 4: Principales géneros de hongos epífitos según altitud y número de muetras

(50\% hialinos), 3 Coelo-mycetes y 1 Ascomycetes. Los principales géneros y sus representantes se muestran en Tabla 1 y Gráfico 5 .

La estructura de los principales géneros integrantes de la comunidad endofítica con mayor frecuencia según número de muestras, presenta ciertos cambios en su composición si se comparan con los otros resultados, 5 de ellos se mantienen en todos los escalones y substratos vegetales, tales como Ulocladium (el más dominante en todos), Penicillium, Cladosporium, Alter-naria, Phoma, Trichoderma, Chaetomium y Fusarium. Aspergillus no se presentó en el último escalón y su presencia máxima fue en el segundo (Gráfico 5).

Dentro de los hongos esporádicos que se presentaron por lo menos en 2 escalones se destaca: Ascochyta sp., Rhizopus oryzae* y Trichoderma longibrachiatum*.(*En Tabla 1).

\section{DISCUSION}

\section{A) Generalidades}

La biodiversidad en la naturaleza está directamente relacionada al estrés de los ecosistemas y en este sentido, las zonas desérticas y andinas pueden considerarse en los límites de los ambientes extremos, donde los patrones altitudinales de la cordillera de los Andes en esas latitudes muestran sustanciales variaciones en estacio-nalidad, pluviosidad, radiación solar y viento, que permiten solamente la sobrevivencia de microorganismos adaptados a estas cambiantes condiciones (Hoffman \& Parson, 1991). Bisset \& Parkinson (1979), consideran en la distribución de geohongos en suelos alpinos, que la temperatura, humedad, el potasio disponible y el $\mathrm{pH}$, son los mayores determinantes en la estructura de la comunidad fúngica de altura. En nuestro estudio el pH de los suelos fué disminu-

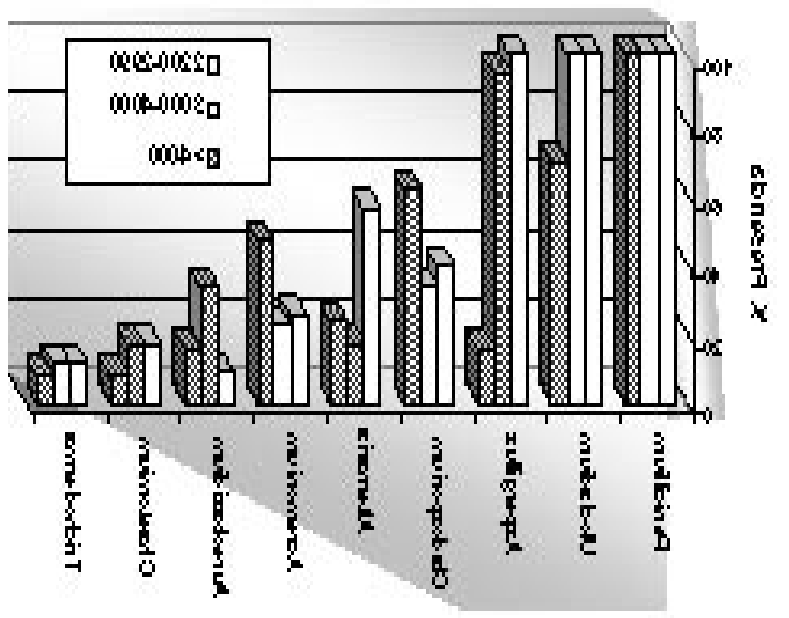

Gráfico 5: Principales géneros de hongos endófitos según altitud y número de muestras

yendo con la altura, situación que pudo haber influenciado la presencia mayoritaria de los Onygenales en el primer y segundo escalón. LLama la atención que C.tropicum, a pesar de considerarse un acidófilo, sólo se encontró en los suelos más alcalinos del primer escalón (Ulfig et al., 1997).

Debido a la variabilidad ambiental, la heterogeneidad espacio temporal en los ambientes desérticos afecta la composición y riqueza de especies de las comunidades (Polis, 1991), sin embargo, debido al empleo de metodologías diferentes, pudimos observar un alto número de especies en todas ellas, especialmente hasta los $3000 \mathrm{~m}$, donde la riqueza más que la composición de la comunidad, tiende a decrecer numéricamente en la cantidad de propágulos presentes en todos los substratos en forma directamente proporcional a la altitud (Ebner $e t$ al., 1989, 1992). Esta disminución de la comunidad andina puede asociarse a los severos factores climáticos, pero también en cierta medida a la menor cantidad de muestras colectadas en los escalones más altos si se comparan con las del primer escalón.

La población asociada con los diferentes substratos en las diversas altitudes y localidades geográficas, exhibieron un grupo de especies en común que presentaron sólo alteraciones en frecuencias o densidades, lo que sugiere que las condiciones ambientales aumentan la habilidad competitiva de algunos taxa propios del suelo que no se afectan por los cambios o la disminución en la cobertura vegetal.

\section{B) Onygenales queratinofílicas/liticas y anamorfos asociados.}

La presencia de hongos geofílicos capaces de utilizar diferentes substratos como la queratina u otros componentes del pelo, está condicionada por numerosos factores 
que involucran principalmente la composición del suelo, la disponibilidad de los recursos, la flora y fauna presente y las condiciones climáticas reinantes (Arnold,1997). Sin embargo, la mayoría de los datos referentes a su distribución geográfica se han obtenido en zonas bajas o inferiores a los $1500 \mathrm{~m}$, especialmente en suelos no desérticos donde el factor altura no actúa en la selección de las comunidades tolerante al estrés, con las limitantes similares de los ambientes extremos, influen-ciados además por la disminución de oxigeno, el empobrecimiento de los suelos y el gradiente térmico y solar cada vez más severo.

Los Onygenales y sus anamorfos relacionados, se presentan en diferente tipos de suelos, desde los ricos en humus a los pobres en materia orgánica, sin embargo, su distribución guarda una relación más estrecha con los suelos asociados a las actividades humanas (Chmel et al., 1972; Soo-Hoo,1991) o al tipo de queratina presente en ellos (De Vroey, 1968; Pugh \& Evans, 1970; Kaul \& Sumbali, 2000).

Nuestras expectativas, estimaron un mayor número de aislamientos de Onygenales y taxa relacionados en todas los escalones altitudinales, sin embargo, nuestros resultados demuestran que las condiciones climáticas invernales y la altura pueden afectar su prevalencia en los meses fríos. El aislamiento de especies de Chrysosporium, Trichophyton, Malbranchea y Geomy-ces, son frecuentemente reportadas por diferentes autores en muchos países y climas, incluyendo las zonas antárticas (Alteras \& Evolceanu, 1969; Abdel-Fattah et al.,1982; Cano et al., 1985; Caretta et al., 1992; Mercantini et al., 1993) El clima antártico, considerado como un desierto frío, coincidentemente semeja en muchos aspectos al andino, que presenta bajas temperaturas, periodos cortos de crecimiento de los microorga-nismos, reducción de hábitat y escasa o nula pluviosidad en las latitudes estudiadas. Sin embargo, los integrantes del género Auxarthron, parecen tener una distribución más restringida, debido a que no son reportados con mucha frecuencia y aparentemente se han detectado mayoritariamente en el hemisferio norte, como en USA, Europa y Asia. (Domsch et al., 1980; Currah, 1985). La presencia de especies de Auxarthron fueron registradas con anterioridad en diversas latitudes de los Andes chilenos, A.conjugatum en zonas altas ( $18^{\circ}$ Lat.S, a 4500$)$, A.umbrinum ( $33^{\circ}$ Lat.S a $\left.3300 \mathrm{~m}\right)$ y A.californiense, A.conjugatum y $\boldsymbol{A}$ umbrinum en zonas xéricas y mésicas bajo los $1000 \mathrm{~m}\left(26^{\circ}\right.$ a $30^{\circ}$ Lat.S) (Piontelli et al., 1986, 1990; Piontelli \& Caretta, 1974). Al parecer los integrantes del género al parecer desarrollan mejor sus capacidades adaptativas que las competitivas (debido a su lento crecimiento), reflejándose en los nuevos hallazgos de, A.conjugatum, A. zuffianum y A umbrinum entre los 2200 y $4000 \mathrm{~m}$. El género Auxarthron y otros Onygenales tienen anamorfos en el género Malbranchea y 3 de sus especies integrantes se aislaron al igual que Auxarthron en las mismas altitudes. Bowman et al. (1996), estudiando ciertos hongos patógenos humanos y sus relativos cercanos no patogénicos, demostraron mediante análisis molecular y con un fuerte soporte estadístico (100\%), que A.zuffianum presenta estrechas relaciones evolutivas con $\boldsymbol{M}$. dendritica (aislada 2 veces entre los 2200-3000m), considerada su anamorfo estrechamente relacionado, así como entre $\boldsymbol{C o c}$ cidioides immitis y Uncinocarpus reesii (95\%) que presentan ambos anamorfos similares en Malbranchea (opinión también confirmada por otros autores, entre ellos Sigler et al., 1998). Como comenta Bowman et al.(1996), dentro del pequeño grupo de los Onygenales, los hongos con o sin su estado sexual en sus ciclos de vida se encuentran entremezclados y se presume que $\boldsymbol{M}$. dendritica y Coccidioides immitis, han perdido en forma independiente la habilidad de reproducirse sexualmente después de apartarse de sus relativos sexuales (A.zuffianum y $\boldsymbol{U}$. reesii), una situación ya observada entre varios grupos relacionados de Hyphomycetes (Lo Buglio et al., 1993).

Malbranchea anamorfo de $\boldsymbol{U}$. reesii, se aisló sólo en el primer escalón altitudinal, fue también reportada mayoritariamente como un taxon dominante y constante entre los 18 y $26^{\circ}$ Lat.S por Piontelli et al.(1990), en zonas costeras y pre-montañosas chilenas, presentándose como holomorfo solo en $1 / 4$ de los aislamientos, sin embargo, su presencia parece disminuir en latitudes más lejanas 30-34 Lat.S. En trabajos nacionales anteriores no se aisló ni en zonas costeras ni en zonas altoandinas entre los 18-19 y $33^{\circ}$ Lat.S (Piontelli \& Caretta, 1974: Piontelli et al., 1986). En la literatura este hongo ha sido frecuentemente reportado en todos los continentes y por ende su distribución (en especial la de su anamorfo) es al parecer cosmopolita, sin embargo, con anterioridad al trabajo de Sigler \& Carmichael (1976), la literatura relacionaba sus aislamientos como cepas desconocidas de Malbranchea o formas conidiales de Gymnoascaceae diversas, como lo indican las referencias de estos autores. Su presencia en muchos tipos de suelos, desde los ricos en materia orgánica a los desérticos y volcánicos, en el pelaje y plumaje de ciertos roedores y aves, así como su sobrevivencia a altitudes intermedias $(<3000 \mathrm{~m})$, convierten a este taxon en uno de los saprotrofos con altas capacidades competitivas en los sustratos queratínicos (Caretta et al., 1977; Hubalek, 2000).

Entre los taxa más registrados Geomyces pannorum, se aisló en todos los gradientes altitudinales. Esta especie y sus variedades fueron anteriormente reportadas en suelos chilenos en otras latitudes de la zona norte y central (Piontelli \& Caretta, 1974; Piontelli et al., 1986; 1990), demostrando sus amplias capacidades adaptativas ya sea bajo los aspectos nutricionales, competitivos y climáticos, que le han permitido una vasta distribución biogeográfica cosmopolita, detectada con diversas técnicas de aisla- 
miento en variados ambientes, desde los suelos fértiles a contaminados o desérticos, hasta los climas extremos como los antárticos. Cuando la temperatura decrece la comunidad de Hyphomycetes tiende a declinar y Geomyces aumenta su presencia, coin-cidiendo con los estudios efectuados en climas fríos. El estrés altitudinal no parece ser un impedimento para que integre la comunidad de los suelos como un organismo oligotrófico de comportamiento psicrotrófico y psicro-tolerante (Nordgren \& Soderstrom,1985;.Del Frate \& Caretta, 1990; Ebner et al., 1992; Mercantini et al., 1993; Bergero et al.,1999). Esta capacidad adaptativa se destaca aún más al detectarse su crecimiento en ciertos grupos de comunidades fúngicas bajo las extremas condiciones de contaminación radioactiva (More, 2001).

El género Gymnascella, Trichophyton y Amauroascus, tuvieron bajos registros en nuestra investigación. Se esperaba un predominio de especies de Chrysosporium junto con los integrantes del complejo Arthroderma qua-drifidum (Trichophyton terrestre), sin embargo, el primero sólo fue representado por C.tropicum en verano en el escalón más bajo, sin la presencia de un teleomorfo asociado. Esta especie cosmopolita, que se aisla frecuentemente en diversos tipos de suelos, desde los fértiles a los áridos y alcalinos, integrando la comunidad queratino-lítica con T.terrestre u otros especies de Chrysoporium, son consideradas como especies constantes y dominantes (euridominante) en toda la zona norte del país, desde la costa a las zonas precordilleranas (Piontelli et al.,1990) pero también con una menor presencia, en una zona cordillerana central sobre los $3000 \mathrm{~m}$. Ambos taxa, parecen no adaptarse a altitudes superiores a los $4000 \mathrm{~m}$, salvo bajo ciertas condiciones especiales como en los suelos enriquecidos por la presencia de abundantes flora y fauna (aves y roedores), en especial T.terrestre, que fue la especie dominante en una zona altoandina (alrededor del lago Chungará a $4500 \mathrm{~m}$ ) (Piontelli et al.,1986). Domsch et al.(1980), comentan que T. terrestre parece tener preferencia por zonas subtropicales y temperadas y prácticamente no se ha aislado en zonas antárticas.

\section{C) Queratinofílicos no relacionados con los Onygena- les.}

La abundante riqueza de especies de la comunidad queratinofílica, confirman que los ecosistemas desérticos tienen más especies de la que uno puede predecir para éstos hábitat cuyas condiciones abióticas seleccionan una comunidad tolerante al estrés (Wicklow, 1981). El empleo de la sencilla y poco laboriosa técnica del anzuelo queratínico, fue suficiente para determinar la alta versatilidad nutricional (diversidad funcional) de los organismos xéricos (Gochenaur,1975), especialmente las capacidades celulolíticas de algunas especies al utilizar ya sea, los componentes del anzuelo queratínico o la celulosa en la mayoría de las altitudes estudiadas, principalmente en algunos integrantes del género Acremonium y Penicillium (en especial P. raciborskii), Alternaria alternata, Aspergillus fumigatus, Emericella nidulans, Cladosporium cladosporioides, Phoma glomerata, Ulocladium atrum y U.chartarum. Estos taxa mayoritariamente saprotrofos, pueden considerarse bajo la categoría de verdaderos hongos autóctonos propios del suelo y del filoplano, adaptados a las condiciones de estrés que prevalecen en este ambiente andino (en especial Penicillium sobre los $4000 \mathrm{~m}$ ), siendo capaces de ocupar una amplio rango de hábitat, de actuar en situaciones ecológicas especiales, de adaptación a una vida libre, con pocas tendencias a la simbiosis e integrando grupos ecológicos bien definidos que exhiben en conjunto características de psicrotolerantes, termotolerantes, xerotolerantes y halotolerantes (Cooke \& Rayner, 1984, Moubasher et al.,1990). Muchos de los géneros geofíli-cos de presencia esporádica parecen no establecer una población permanente en los suelos en los diferentes escalones altitudinales y sólo sobreviven en períodos climáticos cortos favorables en algunos hábitat protegidos, asociados a diversos substratos vegetales o a la dispersión de la queratina, especialmente aportada por las aves en las zonas más altas. (De Vroey, 1968; Piontelli et al., 1986; Moser, 2002).

Debemos destacar la importancia de 5 géneros que demostraron en orden decreciente una alta selectividad y la más alta prevalencia hacia este substrato tales como: Ulocladium, Penicillium, Aspergillus, Acremo-nium y Cladosporium.

Ulocladium, fue el taxa más dominante, en especial el grupo $\boldsymbol{U}$. atrum y $\boldsymbol{U}$ chartarum. Hay pocos reportes de la presencia de estas 2 especies y otros integrantes a diferentes altitudes, generalmente se detectan en climas tropicales y templados en varios tipos de suelos, incluso los salinos y desérticos (Moubasher et al; 1985,1990; Abdel-Hafez, 1981), sobre el filoplano, la hojarasca senescente, la madera o los suelos áridos y semidesérticos, los cuales, generalmente presentan un buen número de especies de Hyphomycetes con dictioconidios dematiáceos (Simmons, 1981). Son 2 especies saprofíticas cosmopolitas y en especial U.atrum se reconoce en la literatura como un antagonista sapro-fítico de Botrytis cinerea, capaz de inhibir la esporu-lación de este importante fitopatógeno (Köhl et al., 1995; Kessel et al., 1999).

Todos los aislamientos que por las características macro y microscópicas en PDA correspondieron al grupo U.atrum, se clasificaron solamente en estado maduro a nivel de grupo. Debido al elevado número de cepas, estas se guardaron para un próximo estudio de la múltiple morfología de sus conidios en etapas tempranas de desarrollo, según el ultimo tratamiento de Simmons (1998) y a un análisis genético comparativo con biología molecular 
(PCR).

La composición de la comunidad fúngica hallada en el escalón más alto, se asemeja en estructura a la de la zona lacustre del norte chileno superior a los 4000m (Piontelli et al.1986), donde los integrantes del género Ulocladium, Penicillium Acremonium, Alternaria y Aspergillus, mantienen frecuencias de presencia similares. Las especies de Aspergillus y algunos de sus teleomorfos predominan en el escalón inferior, en especial A.fumigatus, A.versicolor, A.ustus y Emericella nidulans, disminuyen en el segundo, pero están prácticamente ausentes en el tercero salvo A.fumigatus. Puede observarse que el suelo desértico en los escalones más altos no ofrece las mejores condiciones como reservorio de los propágulos de dispersión de los integrantes de este género, a pesar de su conocida capacidad xerofílica y halofílica. Estas propiedades a la tolerancia a la falta de agua y las altas concentraciones salinas son comunes en las especies de Aspergillus y Penicillium, pero también obsevadas en algunos de los aislamientos de Ulocladium, capaces de crecer en medios de hasta $10 \%$ de $\mathrm{NaCl}$ y $40 \%$ de Sucrosa, pero tambien a concentraciones de $\mathrm{CuSo} 4(1 \mathrm{~g} / \mathrm{l})$ y $\mathrm{AsO} 2$ $(0,225 \mathrm{~g} / \mathrm{l})$ (datos no presentados).

Los integrantes del género Penicillium, Alter-naria y Cladosporium, considerados como especies de gran amplitud por sus capacidades adaptativas, competitivas y antagónicas, que les permiten una alta presencia en los suelos y en la vegetación, también se han aislado desde la micota anemófila en ambientes alpinos mediante estudios gravimétricos y volumétricos junto a otros géneros tales como Acremonium, Epicoccum, Phoma, Fusarium y Aureobasidium, entre otros (Ebner et al., 1992). Algunas de las especies de Acremonium, parecen mantener una frecuencia de presencia y constancia en todos los escalones altitudinales, sin embargo, los integrantes del género Alternaria (en especial A.alter-nata) parecen afectarse con la altitud. El comportamiento de Cladosporium cladosporioides sobre la queratina fue particular, debido a que su mayor presencia fue en las zonas más altas. Al parecer la capacidad de colonización del substrato queratínico estaría limitada por la comple-jidad de sus componentes o por la mayor presencia y competencia de otros hongos en zonas bajas, como lo demuestra su mayor preferencia, presencia y constancia por el susbstrato vegetal en los diferentes escalones. Cladosporium es un género muy bien adaptado a los habitat rigurosos y por su condición de dematiáceo posee junto a Alternaria alternata y Epicoccum nigrum una gran tolerancia a la desecación (Hudson, 1986). El comportamiento de Penicillium en los diferentes escalones fue bastante similar, sin embargo, debido a la diversidad de especies aisladas, no fue posible determinar todos sus integrantes, situación que no permitió reconocer la posible dominancia de algunas especies en la época de mayor presencia (verano).

Fusarium equiseti, Phoma glomerata y Chaetomium spp., presentaron un comportamiento similar en el escalón más bajo, pero a mayores altitudes, tienden a desaparecer. Estos taxa ubicuos y marcadamente celulolíticos, muestran también una tendencia a la queratinofilía, especialmente Chaetomium, donde su afinidad por este substrato puede considerarse como selectiva (Piontelli \& Caretta, 1974; Kaul \& Sumbali, 2000). Phoma glomerata, común en todo tipo de material vegetal y también en el suelo, presentó mayorita-riamente dictioclamidosporas, en cadenas simples o ramificadas (Figura 5). La presencia de picnidios fue escasa y éstos sólo se observaron tardiamente en los subcultivos, demostrando su capacidad adaptativa ante el estrés ambiental.

\section{D) Epífitos.}

El ambiente del filoplano y las superficies de otras partes aéreas de los vegetales, como los tallos de pastos de gramíneas silvestres, soportan una micota, caracterizada por los cambios en su composición debido a la acción de factores climáticos y nutricionales estacio-nales, no representando un ambiente estable, sino un hábitat con alto estrés caracterizado por un disturbio periódico y constante en el tiempo (Cooke \& Rayner, 1984). Una gran variedad de propágulos fúngicos originarios del suelo o de las superficies de los vegetales se depositan como epífitos debido a la acción del viento, conformando una comunidad transitoria o una residente adaptada a una larga sobrevivencia en las duras condiciones que prevalecen en la zona.

La observación directa de los hongos de la filósfera y otras partes aéreas mediante técnicas de aislamiento y cultivo, ha permitido describir poblaciones y comunidades fúngicas en la flora de muchas y diversas zonas geográficas (Lamb \& Brown, 1970; Dickinson \& o'Donnell, 1977; Cabral, 1985; Thomas \& Shattock, 1986). La constante presencia y persistencia de algunas especies, principalmente: Acremonium strictum, Cla-dosporium cladosporioides, Penicillium raciborskii, Ulocladium atrum, U.botrytis y Alternaria alternata complex, en todas las altitudes, que aumentaron su presencia en relación al número de muestras en el gradiente más alto, puede asociarse a su condición de residentes inespecíficos con activa participación en la degradación primaria del substrato al inicio de la senescencia. Por su producción constante de sus esclerocios, Penicillim raciborskii, permitió un fácil seguimiento en las placas con el substrato vegetal y sus aislamientos permitieron reconocer sus capacidades adaptativas y de dispersión en todos los escalones altitudinales. La mayor presencia fúngica detectada en invierno ( $>100 \%)$ en el gradiente más alto, debido a un aumento de las especies esporádicas, no alteró la dominancia en la estructura de la comunidad y puede considerarse como una respuesta estacional en la 

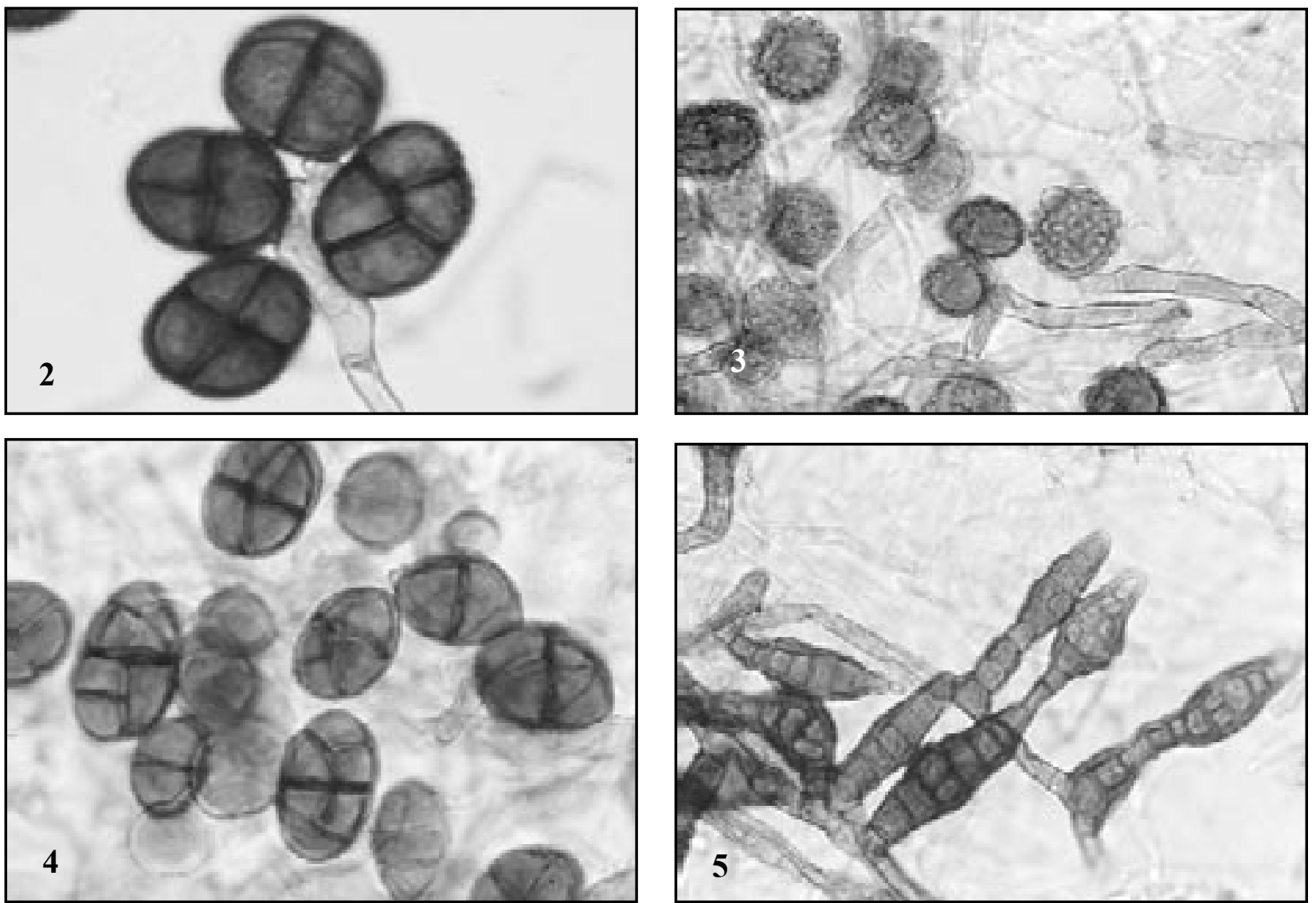

Fig.2,3,4,5. 2.- Ulocladium atrum, conidióforo y conidios $x 1000$. 3.- U.tuberculatum, conidióforos y conidios 1000x. 4.- $\boldsymbol{U}$. consortiale conidios $1000 x$. 5.- Phoma glomerata clamidosporas en el micelio 1000x.

distribución temporal de la abundancia frente a los variados factores ambientales que controlan la llegada de las esporas a las superficies de los vegetales, su esporulación y crecimiento (Breeze \& Dix, 1981). En este sentido las especies de Aspergillus, Aureo-basidium y Chaetomium fueron las más afectadas (Grafico 3). En zonas desérticas, la estructura de la comunidad epifítica parece guardar características similares a la del suelo, debido a que el substrato orgánico está representado mayoritariamente por los escasos restos de vegetales presentes.

Los hongos con altas frecuancia de presencia corresponden a especies mayoritariamente saprófitas y algunas parásitas que compiten por el mismo recurso común, principalmente sobre las especies vegetales de Atriplex, Ephedra y Fabiana, adaptando sus estrategias (estrés tolerantes o «ruderal») acorde a las condiciones ambientales del momento, no sólo actuando como epífitos sino también como endófitos en las etapas previas a la senescencia.

\section{E) Endófitos.}

Petrini (1991), amplía el concepto de endófito incluyendo a todos los organismos que habitan los órganos de las plantas que en una etapa de su vida son capaces de colonizar sus tejidos internos sin causar una daño aparente en ellos. Los trabajos ecológicos sobre endófitos fúngicos de los tejidos y partes aéreas de las plantas, principalmente Clavicipitales en regiones temperadas, se han efectuado básicamente sobre importantes gramíneas cultivadas y silvestres (Clay 1990), sin embargo, hay marcadas diferencias en la composición de especies en relación a la distribución geográfica y el clima.

La variación de la composición de la comunidad endofítica en relación a la altura es coincidente con los conceptos generales de sus cambios en dependencia de las localidades y condiciones ecológicas regionales y que la mayoría de los taxa encontrados corresponden a especies de epífitos comúnmente considerados como saprófitos primarios de muchas plantas, capaces de colonizar los tejidos del vegetal vivo mediante algún tipo de especificidad con su hospedero (Petrini 1987, 1991). Esta situación permite una mejor protección frente a las condiciones ecológicas adversas (irradiación, desecación) evitando las actividades antagónicas de otros organismos más competitivos pre- 
sentes en la superficie. Varios taxa con altas frecuencias de presencia en los substatos queratinofílicos y vegetal (epífitos) no se detectaron como endófitos, o sus presencias disminuyeron, en especial los que no poseen paredes melaninizadas, más resistentes a los rayos UV, como: Acremonium, Asper-gillus y Emericella nidulans.

Los dematiáceos como Alternaria alternata, Cladosporium cladosporioides, C.herbarum y Epi-coccum nigrum, son epífitos conocidos por su capacidad de penetrar los tejidos vivos e inducir la senescencia. Estos saprófitos primarios comunes que se aíslan de las superficies de material vegetal esterilizado diverso, son frecuentes en zonas temperadas y raros en las zonas tropicales, donde se observa una gran abundancia de saprofitos y patógenos compitiendo por el material vegetal muerto, considerado la mayor fuente de inóculo para los potenciales endófitos (Isaac et al.,1993). En nuestro estudio, se detectó la presencia constante de $\boldsymbol{C}$.cladospo-rioides en todas las altitudes y el reemplazo de A.alter-nata en el escalón más alto por A.chlamydospora, pero también se observó la presencia de los integrantes del género Uocladium, Chaetomium, Fusarium, Peni-cillium (en especial P. raciborskii) y Phoma, reconocidos como endófitos en plantas, arbustos y hierbas diversas (Dickinson, 1981; Petrini 1986; Ballero et al, 1999). El comportamiento de Epicoccum nigrum, escasamente presente sólo en el escalón más alto en las 3 metodo-logías, es poco explicable; se le considera un invasor secundario de tejidos vegetales dañados o senescentes y su presencia en una gramínea no determinada, podría reflejar algún grado de asociación.

Podemos afirmar que la composición de la comunidad endofítica encontrada es muy similar en las 3 altitudes, pero la adaptación de su microbiota al clima andino y su constitución principalmente integrada por Hyphomycetes comunes en diversos hospederos vegetales y aparentemente no especie-específicos, refleja la magnitud de los diversos tipos de estrategia econutricional de sus integrantes. En este sentido, las regiones desérticas resultan interesantes para el conocimiento, distribución y ecología de este grupo fúngico que debido a sus importantes roles biológicos pueden ser un factor favorable en los ciclos de vida de los vegetales presentes en estos hábitat.

\section{CONCLUSIONES}

La dispersión en todos los gradientes altitu-dinales se efectuó principalmente por mitosporas de Hyphomycetes, con una mayor presencia de géneros con propágulos dematiáceos en los substratos queratínicos y hialinos sobre el substrato vegetal.

A pesar que el gradientes climático altitudinal en zonas desérticas actúa sobre la estructura de la comunidad fúngica, esta parece exhibir condiciones de estabilidad, donde un grupo de especies pertenecientes a los géneros
Ulocladium, Penicillium, Aspergillus, Acremonium y Alternaria muestran con pequeñas oscilaciones, una constancia y sobrevivencia en el tiempo en todos los escalones. La dominancia de algunos de los integrantes de este reducido grupo de taxa en todos estos escalones, fue compartida en el tiempo con una proporción mayoritaria de especies esporádicas o de baja frecuencia ("ruderal") en estrecha relación con los escasos substratos presentes en el suelo o la litera vegetal senescente. Esto, que puede asociarse al concepto de un balance dinámico de la comunidad, parece corresponder a un patrón netamente regional más que local, confirmando que las regiones áridas y semiáridas son menos afectadas por los cambios globales climáticos y las actividades humanas que las áreas mésicas.

Los Onygenales y anamorfos relacionados se aislaron principalmente en verano y en los escalones más bajos, prevaleciendo las especies de Auxarthron, mientras Geomyces pannorum fué la especie de mayor presencia y persistencia en todos los escalones.

Nuestra investigación confirma que el anzuelo queratínico y el substrato vegetal autóctono, usados simultáneamente, permiten apreciar en buena medida la actividad ecológica y la capacidad de algunos hongos de subsistir en el ambiente ya sea como integrantes de la microbiota del suelo, como epífitos o como endófitos tolerantes al estrés y de comportamiento principalmente saprotrofo, capaces de utilizar substratos complejos en diferentes hábitat.

\section{REFERENCIAS}

Abdel-Fattah,H.M.;Mobasher,A.H. \& Maghazy,S.M. (1982). Keratinolytic fungi in Egyptian soils. Mycopathologia 79:49-53

Abdel-Hadez, S.I.I. (1981). Halophilic fungi of desert soils in Saudi Arabia. Mycopathologia 61:75-80

Alteras,I. \& Evolceanu, R.(1969). A ten years survey of Romanian soil screening for keratinophilic fungi (1958-1968). Mycopath.Mycol. Appl. 38:151-160

Arnold,E.J. (1997). Biogeography and consevation. In: Wicklow,D.T.\& Soderstrom,B (eds.) The Mycota Vol.IV.Environmental and Microbial relationships. Springer -Verlag, Berlin. Pp.115-131

Ballero,M.; Sponga,F.; Ariu, A. \& Madau,P. (1999). Distribuzione ed aspetti ecologici di funghi endofiti presenti in specie sclerofilliche mediterranee. I contributo. Micologia Italiana 3:5-9

Bergero,R.; Girlanda,M.; Varese,G.C.; Intili, D.; Luppi,A.M. (1999). Psychrooligoytrophic fungi from antarctic soils of Franz Joseph Land. Polar Biology 21:361-368

Bissett, J. \& Oarkinson, D. (1979). Functional relationships between soil fungi and environment in alpine tundra, Can. J. Bot. 57: 1642-1659

Breeze,E.M. \& Dix, N.J. (1981). Seasonal analysis of teh fungal community on Acer platanoides leaves. Trans. Br. mycol. Soc. 77:321-328

Cabral,D. (1985). Phyllosphere of Eucalyptus viminalis: Dynamics of 
fungal population. Trans. Br. mycol. Soc. 85:501-511

Cano,J.;Punsola,L.\& Guarro,J. (1985). Distribución geográfica, según climas y tipos de suelo, del género Chrysosporium en catalunya. Rev. Iber. Micol. 2:91-108

Caretta,G.; Del Frate, G.; Piontelli, E. \& Todaro, F. (1977). Distribuzione di funghi cheratinofili nel suolo del vulcano Etna (Sicilia). Rivista di Parassitologia 23:115-127

Caretta, G.; Mangiarotti, A.M. \& Piontelli, E. (1992). Keratinophilic fungi isolated from soil of Italian parks in the province of Pavia. Eur J. Epidemiol. 8:330-339

Chmell,L.;Hasilikova,A.;Hrasko,J. \& Vlacilikora, A.(1979). The influence of some ecological factors on keratinophilic fungi in soil. Sabouraudia 10:26-36

Clay, K. (1990). Fungal endófites of grasses. Ann. Rev. Ecol. Syst. 21: 275-297

Cooke,R.C. \& Rayner, A.D. (1984). Ecology of saprotrophic fungi. Longaman, London and N.York.

Christensen, M. (1981). Species diversity and dominance in fungal communities. In: Wicklo, D.T. \& Carroll,G.C.(Eds.) The fungal community, its organization and role in the ecosystem. Marcel Dekker, Ink. N.York, pp.201-233

Currah, R.S. (1985). Taxonomy of the Onygenales: Arthrodermataceae, Gymnoascaceae, Myxotrichaceae and Onygenaceae. Mycotaxon $24: 1-216$

Del Frate,G. \& Caretta,G. (1990). Fungi isolated from antarctic material. Polar Biology 11:1-17

Dickinson, C.H.\& O'Donnell,J. (1977). Behaviour of phylloplane fungi on Phaseolus leaves. Trans. Br. mycol. Soc. 68:193-199

Dickinson, C.H. (1981). Biology of Alternaria alternata, Cladosporium cladosporioides and C.herbarum in respect of their activity on green plant. In: Blakeman,J.P.(Ed.), Microbial ecology of the phylloplane. Academic Press, London. pp 169-184

Domsch,K.H.; Gams,W. \& Traute-H,A. (1980). Compendium of soil fungi. Vol 1. Academic Press. London.

Ebner,M.R.; Haselwandter, K. \& Frank, A. (1992). Indoor and outdoor incidence of airborne fungal allergens at low and high-altitude alpine environment. Mycol. Res. 96:117-124

Gochenaur, S.E. (1975). Distribution patterns of mesophilous and thermophilous microfungi in two Bahamian soils. Micopat. and Mycol. Appl. 57:155-164

Hoffman, A.A. \& Parson, P.A. (1991). Evolutionary genetics and environmental stress. Oxford University Press. N.York.

Hubalek, Z. (2000). Keratinophilic fungi associated with free-living mammals and birds. In: Kushwaha, R.K.S. \& Guarro, J. (Eds.) Biology of Dermatophytes and other keratinophilic fungi. Revista Iberoamericana de Micología, Bilbao. pp. 93:103

Hyde,K.D.; Cerous,P.W.; Lee,S.; Lumyong,G.; McKenzie, E.H.C. \& Paulus,B. (2002) Diversity of saprobic microfungi. Sevent Inter. Mycol. Cong. Abstract $n^{\circ} 100$. Olso. Norwey.

Isaac, S.; Frankland, J.C.; Watling, R. \& Walley, A.J.S. (Eds.) (1993). Aspects of tropical mycology. Cambridge University Press: Cambridge, U.K.

Kaul,S. \& Sumbali,G. (2000). Keratinophilic fungi from feathers of Indian poultry birds. Mycologist 14:148-150
Kessel, G.J.T.; de Haas, B.H.; Lombaers-van der Plas,C.H.; Meijer, E.M.J.; Dewey, F.M.; Goudrian, J.; van Der Werf, W. ; Köhl, J. (1999). Quantification of micelium of Botrytis spp. and the antagonist Ulocladium atrum in necrotic leaf tissue of Cyclamen and Lily by fluorescence microscopy and image analysis. Phytopathology 89:868-876

Kjoller,A. \& Struwe,S. (1992). Functional groups of microfungi in decomposition . In:Carrol,G.C.\& Wicklow,D.T. The Fungal community: Its organizations and role in teh ecosystem. II Ed. Marcel Dekker, N.Y. pp.619-630

Körner,C. (1999). Alpine plant life. Functional plant ecology of high mountain ecosystems. Springer, Verlag.

Köhl,J.; Molhoek,W.M.L.;van der Plas, C.H. \& Fokkema, N.J. (1995). Effect of Ulocladium atrum and other antagonists on sporulation of Botrytis cinerea on dead lily leaves exposed to field conditions. Phytopathology 85:393-341

Lamb,R.J. \& Brown,J.F. (1970). Non parasitic microflora of leaf surfaces of Paspalum dilatatum, Salix babylonica and Eucalyptus stellulata. Trans. Br. mycol. Soc. 55:383-390

LoBuglio, K.F.; Pitt, J.I. \& Taylor, J.W. (1993), Phylogenetic analysis of two ribosomal DNA regions indicates multiple independent lossess of a sexual Talaromyces state among a sexual Penicillium species in subgenus Biverticillium. Mycologia 85:592-604

McGinnies,W.G. (1979). Arid-land ecosystems-common features troughout the world.In: Goodal,D.W.;Perry,R.A \& Howes,W. (Eds.)Arid-Land ecosystems:Structure,functioning and management,Vol.I, Cambridge Univ. Press,U.K. pp.299-316

Mercantini,R.; Marsella,R.; Moretto,D.\& Finotti, E. (1993).Keratinophilic fungi in the antarctic environment. Mycopathologia 122:169175 .

More,R.T.(2001).Hot fungi from Chernobil The Mycologist 15:63-64

Moser, M. (2002). Alpine fungi of tundra. Seventh Intern. Mycological Congress, Abstracts. August Oslo.

Moubasher, A.H.; Abdel-Hafez, S.I.I.\& El-Maghraby, O.M.O.(1985) Studies on soil mycoflora of Wadí Bir-El-Ain, eastern desert, Egypt. Cryptogamie Mycologie 6:129-143

Moubasher, A.H.; Abdel-Hafez, S.I.I.; Bagy,M.M.K. \& Abdel-Star, M.A. (1990). Halophilic and halotolerante fungi in cultivated desert and salt marsh soils from Egypt. Acta Mycologica 26:65-81

Nordgre, A.E.B. \& Soderstrom, B. (1985) Soil microfungi in an area polluted by heavy metals. Can. J. Bot. 63:448-455

Petrini, O. (1986). Taxonomy of endophytic fungi of aereal plant tissues. In: Fokkema, N.J.\& van den Heuvel,J. (Eds.) Microbiology of the phyllosphere. Cambridge University Press, UK. pp175-187

Petrini, O. (1987). Endophytic fungi of alpine Ericaceae. The endophytes of Loiseleira procumbens. In: Lauresen,G.A.; Amirati,J.F. \& Redhead,S. A. (Eds.), Artic and alpine Mycology II. Environmental science Research. Vol 34. Plenum Press. N.York and London. pp.71-77

Petrini, O. (1991). Fungal endophytes of tree leaves In. Andrews, J.H \& Hirano,S.S. (Eds,) Microbial ecology of leaves. Springer-Verlag, PP.179-197

Piontelli, L.E. \& Caretta,G. (1974). Considerazioni ecologiche su alcuni 
geomiceti isolati su substrati cheratinici in localitá montagnose delle Ande del Chile. Riv. Pat. Vegetale 10:261-314

Piontelli, L.E.; Toro, M.A.\& Casanova, Z.D. (1986). Microcomunidades fúngicas en zona altiplánica chilena. Estudio sobre substratos queratínicos.I. Rev. Arg. Micología. 9:26-32

Piontelli, L.E.; Toro, M.A.\& Casanova, Z.D. (1990). Latitudinal distribution of Onygenales and related Hyphomycetes in soils of northern Chile between $18^{\circ}-34^{\circ}$ south latitude. Boletín Micológico 5:79-106

Polis, G.A. (1991). The ecology of desert communities. The University of Arizona Press, Tucson, Arizona.

Pugh,G.J.F.\& Evans,M.D. (1970).Keratinophilic fungi associated with birds I. Fungi isolated from feathers, nest and soils. Trans. Br. Mycol. Soc. 54:233-240

Quintanilla,V.(1983). Geografía de Chile.Tomo III. Biogeografía. Instituto Geográfico Militar. Santiago

Rossman,A.Y.;Tulloss,R.E.; O'Dell,T.E. \& Thorn,R.G. (1998). Preotocols for an oll taxa biodiversity inventory of fungi a Costarican conservation area. Parkway Publishers, Boone, Nord Carolina.

Schlesinger,W.H.; Reynolds,J.F.; Cunningham,G.L.; Huenneke,L. F. Jarrel,W.M.; Virginia,R.A.; Whitford,W.G. (1990). Biological feedbacks in global desertification. Science 247:1043-1048

Shrader-Frechette, K.S. \& McCoy, E.D. (1998). Method in Ecology: Strategies for consevations. Cambridge University Press.

Sigler, L . \& Carmichael, J.W. (1976). Taxonomy of Malbranchea and some other Hyphpomycetes with arthroconidia. Mycotaxon 4:349-488

Sigler,L.; Flis, A.L. \& Carmichael,J.W. (1998). The genus Uncinocarpus (Onygenaceae) and its synonym Brunneospora: new concepts,combinations and connections to anamorphs in Chrysosporium, and further evidence of relationship with Coccidioides immitis. Can. J.Bot. 76:1624-1636

Simmons, E. (1981). Alternaria themes and variations. Mycotaxon 8:16-34

Soo-Hoo,T.S. (1991). Isolation of keratinophilic fungi from Malaysia. Mycopathologia 113:155-158

Thomas, M.R. \& Shattock,R.C. (1986). Filamentous fungal associations in the phylloplane of Lolium perenne. Trans. Br. mycol. Soc. 87:1255-268
Ulfig, K.; Guarro, J.; Cano, J.; Gene, J.; Vidal, P.; Figueras, M.J. (1997). The ocurrence of keratinolytic fungi in sediments of the river Tordera (Spain). FEMS Microbiology Ecology 22:111-117

Vanbreuseghem,R. (1952). Technique biologique pour lísolement des dermatophytes du sol. Ann.Soc.Belge Méd. Trop. 32:173-178

Vroey, C.De. (1968). Ecologie de quelque gymnoascacées keratinophiles (I). Bull. De l'Acad. Royale de Belgique (Classe des Sciences) 54:1352-1368

Wicklow,D.T. (1981). Biogeography and conidial fungi. In:Cole,G.T. $\&$ Kendrich,B (Ed.) Biology of Conidial fungi,Vol.I, Academic press N.Y. pp.417-447 